\title{
O Sistema Impro na sala de aula: escutando as crianças sobre essa prática do teatro ${ }^{1}$
}

The Impro System in the classroom: listening to the children about this practice of theater

Mariana de Lima Muniz ${ }^{2}$ Hortência Campos Maia ${ }^{3}$ 


\section{Resumo}

O sistema de ensino-aprendizagem da improvisação criado por Keith Johnstone, denominado Sistema Impro, vem sendo praticado por artistas-pesquisadores-docentes no Brasil desde o início dos anos 2000. No entanto, no contexto do ensino do teatro na Escola Bási$\mathrm{ca}$, trata-se de um sistema pedagógico pouco explorado. Este artigo apresenta uma pesquisa etnográfica com crianças do ensino fundamental no processo de ensino e aprendizagem do Sistema Impro. Como resultado, avaliou-se que essa prática possibilita o aprendizado de conteúdos específicos do teatro, além de ter se configurado como um momento de uma criatividade "redescoberta" na relação entre os alunos. Espera-se, assim, contribuir sobre o uso do Sistema Impro no ensino de teatro na escola, a partir da prática pedagógica descrita neste trabalho.

Palavras-chave: Sistema Impro; Ensino de Teatro; Ensino Fundamental; Pedagogia do Teatro

\section{Abstract}

The improvisation teaching-learning system created by Keith Johnstone, the Impro System, has been practiced and discussed by artists-researchers-teachers in Brazil since the early 2000s. However, in the context of teaching the curricular subcomponent theater in Basic School, it is a little explored pedagogical system. This paper presents a field research of the teaching experience with elementary school children in the process of teaching and learning Impro System. As a result, it was observed that the Impro System practice allows the learning of specific theater contents, as well as being configured as a moment of "rediscovered" creativity among the students. It is hoped to contribute to the use of the Impro System in teaching theater at schools based on the pedagogical practice described in this work.

Keywords: Impro System; Theater Applied in Education; Elementary School; Theater Pedagogy

\footnotetext{
${ }^{1}$ Este artigo é resultado de pesquisa realizada no Mestrado em Artes de 2013 a 2015, no Programa de Pós-Graduação em Artes, da Escola de Belas Artes, da Universidade Federal de Minas Gerais (UFMG). Seus resultados parciais foram comunicados no VIII Congresso da Associação Brasileira de Pesquisa e Pósgraduação em Artes Cênicas (ABRACE), na cidade de Belo Horizonte, em 2014.

${ }^{2}$ Profa. Ms. da Pontifica Universidade Católica de Minas Gerais - PUC/Minas - hortenciamaiaatriz@gmail.com

${ }^{3}$ Profa. Dra. Departamento de Fotografia, Teatro e Cinema, atuando na Pós-graduação em Artes e Curso de Graduação em Teatro da EBA/UFMG -

marianamuniz32@gmail.com
} 


\section{A Improvisação de Keith Johnstone: o Sistema Impro}

A denominação Impro refere-se às práticas da improvisação teatral diante do público originadas do livro do professor de Teatro e dramaturgo inglês, Keith Johnstone: Improvisation and the theatre (1979). A prática da Impro abarca exercícios, jogos e improvisações necessários para o aprendizado de sua proposta da improvisação como espetáculo (Muniz, 2015).

Sistema Impro é a nomenclatura atribuída pela pesquisadora norte-americana Theresa Dudeck (2013) em relação ao trabalho de ensino-aprendizagem de Johnstone, que se desenvolve desde a década de 1950 até a atualidade. Esse sistema constitui-se em uma série de jogos cuja premissa básica é a expressão, a aceitação e a valoração das próprias ideias e das propostas dos parceiros de improvisação em uma perspectiva de criação que se constrói, coletivamente, a partir da escuta e da capacidade de adaptação dos jogadores, objetivando o que Johnstone denomina "desbloqueio da criatividade" (Johnstone, 2008).

Dudeck, ao conhecer a teoria e a prática do trabalho de Johnstone, entende-o como um sistema, pois compreende que o processo de ensino-aprendizagem da improvisação teatral, criado por ele, configura-se em conceitos, práticas e modos de operar que estão em relação de co-dependência, ou seja, não podem ser trabalhados de forma independente e, nesse sentido, caracteriza-se como um sistema.

Entendemos o Sistema Impro como uma nomenclatura contemporânea criada para definir o trabalho de ensino-aprendizagem da improvisação teatral desenvolvida por Keith Johnstone e sua maneira de perceber e lidar com os processos educacionais.

A improvisação tem sido uma prática recorrente no ensino do teatro no Brasil nas últimas décadas, sendo principalmente vinculada aos Jogos Teatrais de Viola Spolin. É evidente que o trabalho com a improvisação em sala de aula não se restringe às propostas de Spolin, em que pese sua grande capacidade de organização de conteúdos explicitados em seu fichário 4 utilizado por vários professores. Além da metodologia dos Jogos Teatrais, podemos destacar o Teatro do Oprimido, o Jogo Dramático e o Drama como outros referenciais metodológicos que têm contribuído para a ampliação da improvisação em sua perspectiva pedagógica.

Neste artigo, interessa-nos apresentar o Sistema Impro, de Keith Johnstone, como mais um procedimento metodológico na prática da improvisação dentre este corolário de experiências já bastante difundidas no ensino do teatro em nosso país. Não obstante, por percebermos que, embora a influência do trabalho de Keith Johnstone tenha começado a ganhar relevância no Brasil recentemente - mais especificamente desde o início dos anos 2000, com o surgimento de companhias que desenvolvem essa linguagem da improvisação teatral somando-se com trabalhos acadêmicos acerca da temática - ainda há pouco caminho percorrido no que tange à pesquisa da pedagogia desse Sistema.

Com este artigo, esperamos contribuir com para a difusão de uma possibilidade de abordagem pedagógica ou metodológica que contribua para um aprendizado teatral mais criativo e espontâneo, no âmbito do ensino de teatro na escola.

${ }^{4}$ Jogos Teatrais: o fichário de Viola Spolin, 1975. 


\section{Breve historiografia de Johnstone e da criação de seu sistema educacional}

Keith Johnstone é um dramaturgo e professor de Teatro nascido em 1933 em Devon, Inglaterra. Atualmente reside em Calgary, Canadá, onde continua ensinando Impro a estudantes, também de várias partes do mundo, recebendo muitos alunos estrangeiros. Em 1979, publicou seu primeiro livro, Impro: Improvisation and Theatre, que foi traduzido para diversas línguas e é sua obra mais conhecida. Vinte anos depois, levado por uma necessidade de sistematizar melhor seus exercícios e evitar um entendimento ligeiro de sua obra, publicou Impro for Story Tellers (1998).

No início dos anos de 1950, Johnstone se tornou professor de uma escola em Battersea, na periferia de Londres Como era o professor novato, foi indicado a assumir uma turma considerada difícil pelos demais professores. Jonhstone sempre teve um discurso contrário à escola, ele afirma que sua escolarização destruiu sua paixão pela escrita, pois o teria feito se "encaixar" em sistemas pré-estabelecidos de criação

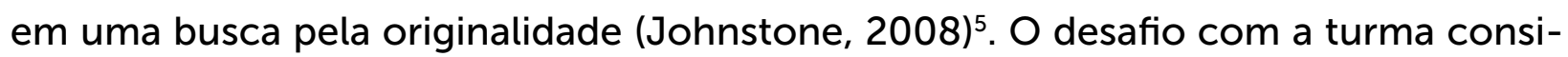
derada difícil o estimulou muito, pois ele acreditava que o ser "difícil" significava não se submeter às regras implícitas e explícitas do sistema escolar. Para o jovem professor, essa dificuldade de adaptação representou uma possibilidade de mudança que o motivou a experimentar novos procedimentos.

Em 1956, Johnstone foi convidado a dirigir um pequeno estúdio de dramaturgia no Royal Court Theatre, em Londres. Concomitantemente, encontrava-se em um grande bloqueio criativo como dramaturgo, segundo ele, devido a seu processo de escolarização que o tornara excessivamente autoconsciente. As experiências como aluno, professor e dramaturgo o levaram a propor uma educação que ele chamou de "reversa". Ou seja, fazer tudo o que seus professores haviam dito que não deveria ser feito.

Em 1970, ele se mudou para o Canadá, onde lecionou na Universidade de Calgary até sua aposentadoria. Nesse contexto, Johnstone desenvolveu, paulatinamente, o que Dudeck (2013) veio a chamar, posteriormente, de Sistema Impro - um conjunto de procedimentos interligados e em interação. Keith Johnstone criou uma série de exercícios de improvisação e adaptou outros. Esses exercícios acabaram se configurando em formatos de espetáculos de improvisação, onde jogos cênicos, calcados na construção de histórias, por exemplo, saíram da sala de trabalho para o palco. Sua primeira experiência foi com o Theatre Machine que, nos anos 1960, circulou toda a Europa com o Theatre Sports ${ }^{6}$. Com sua ida ao Canadá, em 1970, fundou o Loose Moose Theatre e criou outros formatos de espetáculo de improvisação também praticados ao redor do mundo: Gorilla Theatre, Maestro e Life Game.

Atualmente, o International Theatresports Organization - ITI é responsável por

\footnotetext{
${ }^{5}$ Em sua obra lançada em 1979, Improvisation and the theater, o próprio Keith Johnstone nos evidencia esses eventos de sua biografia que se relacionam diretamente com sua forma de pensar a educação e, posteriormente, na criação de seu sistema. (A pesquisa que origina este artigo teve acesso à tradução chilena de sua obra, com edição de 2008.)

${ }^{6}$ Theatre Sports é um formato de espetáculo de improvisação criado por Johnstone que consiste em uma competição entre times em busca da melhor história improvisada. $\mathrm{O}$ formato foi adaptado derivando o Match de Improvisação, dentre outros, e continua a ser praticado em diversos países do mundo. O Match, que é um dos formatos de espetáculos de improvisação mais realizados pelos praticantes da Impro pelo mundo, incluindo o Brasil, foi criado e patenteado por Ivone Leduc e Robert Gravel na década de 1970. 0 espetáculo, em uma mistura entre teatro e esporte, consiste em um jogo em que dois times competem entre si através da realização de cenas improvisadas a partir de títulos dados pelo público. A plateia também determina o resultado do jogo, votando nos times e definindo o placar. Há um trio de arbitragem e 16 faltas que regulamentam o bom funcionamento das improvisações, sendo um referencial de qualidade indispensável para os improvisadores e para o público.
} 
reunir os praticantes dos formatos de improvisação criados por Johnstone em todo o mundo. Em 2014, o ITI criou um setor educacional que tem dado suporte à prática do Sistema Impro em escolas (Muniz; Maia, 2014).

\section{O Sistema Impro no ensino de Teatro}

No Sistema Impro, mais importante do que o exercício que é praticado é como ele é praticado: como o professor conduz sua aula, como se comporta e se relaciona com seus alunos, como promove a aceitação do erro no processo de ensino-aprendizagem e a liberdade expressiva no aluno (Maia, 2015).

Como vimos, Keith Johnstone era professor e se questionava sobre a educação dirigida às crianças. A partir de suas experiências na escola, em que ele percebia situações de uma educação cerceadora da criatividade e da espontaneidade, se perguntava como poderia um processo educacional que se pressupõe desenvolver 0 indivíduo, acabar por "embotar e destruir a sua criatividade?" (Achatkin, 2005, p. 18).

Johnstone considera a criatividade ${ }^{7}$ e a imaginação como inerentes ao ser humano, e seu bloqueio deve-se ao medo do erro, do fracasso, ao medo de não dar as respostas "adequadas" socialmente, de errar e de não corresponder às expectativas dos outros, assim, levando ao bloqueio da capacidade imaginativa. Ele outorga à educação este bloqueio: "Em uma educação normal, tudo está delineado para suprimir a espontaneidade, mas eu queria desenvolvê-la"8 (Johnstone, 2008, p. 03). O objetivo dos exercícios do Sistema Impro é o desbloqueio da imaginação.

Uma metáfora bastante utilizada por ele em suas aulas é a de que a imaginação é como um grande animal, uma besta, uma fera, que está ao nosso lado (Muniz, 2014). Se sempre que este animal tenta mostrar-se lhe batemos no focinho e o mandamos embora, é possível que ele pare de aparecer. Portanto, é preciso saber conviver com a possibilidade do erro como parte inegável de qualquer processo de criação, afinal "se não cometermos erros, provavelmente não chegaremos a fazer nada" (Nachmanovitch, 1993, p.87). Permitir-se errar, permitir-se respostas inadequadas, permitir-se ser repetitivo, ser óbvio. Em outras palavras, parar de tentar ser original.

Segundo Santos (1999), a originalidade é relativamente recente como conceito e como valor na história das artes. Até o Renascimento, a obra de um artista era quase sempre coletiva e é comum que obras atribuídas a uma só pessoa tenham sido realizadas por um conjunto de artistas anônimos. $O$ anonimato é um elemento recorrente em obras artísticas anteriores ao século XVII.

A ideia de autoria e de originalidade estão fortemente conectadas. A partir do Romantismo, com o fortalecimento da burguesia, a afirmação do mérito do indivíduo passa a ser um dos principais valores de uma obra artística. Junto a isso surge a ideia do gênio, do ser humano com capacidades imaginativas superiores em oposição aos demais homens e mulheres comuns.

Apesar do conceito de originalidade ter sido alvo principal das críticas das vanguardas históricas, do modernismo e do pós-modernismo, nosso senso comum con-

\footnotetext{
${ }^{7} \mathrm{O}$ conceito de criatividade é amplamente abordado em diversas áreas do conhecimento e sua discussão em relação à cognição e a como se potencializa sua prática na cotidianidade está em efervescente debate, principalmente no campo da psicologia (Kastrup, 2007). Importante, neste momento, acentuar que este artigo se filia às ideais de criatividade e imaginação de Keith Johnstone (Johnstone, 2008), para a criação de sua prática da improvisação como espetáculo.

8 "En una educación normal, todo está diseñado para suprimir la espontaneidad, pero yo quería desarrollarla". (Tradução nossa).
} 
tinua atrelado ao conceito romântico de gênio. Em outras palavras, à originalidade a à autoria como valores intrínsecos de uma obra de arte.

A ideia de erro, de fracasso, também está intimamente atrelada à de originalidade. Nessa perspectiva, podemos constatar que tudo aquilo que não é original, seria um erro, uma cópia. Sendo assim, como não bater no focinho desta "fera" (a imaginação) que se assoma se não temos certeza se ela virá com a reação adequada, original? Por isso, um dos primeiros componentes das propostas de Johnstone é a valorização da primeira reação a qualquer estímulo, a atenção e aceitação de primeira ideia, como nos evidencia o autor:

Muitos alunos bloqueiam sua imaginação porque temem não ser originais. Acreditam saber exatamente o que é a originalidade [...] O improvisador deve dar-se conta que quanto mais óbvio seja, mais original parecerá [...] mais óbvio seja o improvisador, mais autêntico parecerá. [...] Será muito mais criativo quando aprender a aceitar a primeira ideia9. (Johnstone, 2008, p. 79-80, 82)

É preciso coragem por parte do aluno, ou ator, em deixar que suas primeiras reações apareçam, sem saber exatamente o que será exposto com isso.

Para esse trabalho da valorização da primeira reação ao estímulo e do desbloqueio da imaginação, o Sistema tem por elementos procedimentais: escuta, associação livre, oferta, aceitação e bloqueio, a gangorra de status e criação e quebra de rotinas. Em linhas gerais ${ }^{10}$, a escuta define-se como a atenção do ator improvisador voltada para tudo o que acontece ao redor de si mesmo. Muniz (2015) acrescenta a essa definição de escuta a proposta de uma escuta ativa, ou seja, não apenas estar atento como ser capaz de reagir propositivamente na cena.

Ainda segundo Santos (1999), a associação livre é parte da associação livre de ideias, muito explorada pelos surrealistas, entre outros movimentos das vanguardas históricas. Ou seja, a primeira ideia, imagem ou pensamento que surge a partir da escuta ao estímulo. A oferta é a proposta gerada a partir da associação livre. A aceitação e o bloqueio são as possibilidades de recepção à oferta. Uma oferta pode ser aceita, e assim dar continuidade ao jogo improvisado, ou bloqueada, não aceita, interrompendo o jogo ou mudando drasticamente seu rumo. A gangorra de status é a relação de opressão e/ou submissão estabelecida entre os improvisadores. A imagem da gangorra pretende evidenciar que as relações de opressão e/ou submissão expressas no jogo de status é sempre mutável.

Muniz (2015) amplia a aplicação do jogo da gangorra de status na relação dos improvisadores com os objetos, com o espaço e com o público. A gangorra de status é a construção de uma dramaturgia a partir da possibilidade de variação de status, ou seja, de variação nas relações de submissão/opressão e autoridade (status baixo ou alto nas relações) entre os jogadores e os elementos que os rodeiam. A criação de rotinas é um conceito originário da narrativa e é o primeiro passo necessário para o estabelecimento da cena improvisada: uma oferta é feita por um jogador, essa oferta (ideia) é desenvolvida até seu limite de possibilidades, sendo criada uma rotina no

\footnotetext{
9 "Muchos alumnos bloquean su imaginación porque temen no ser originales. Creen saber exactamente lo que es la originalidad [...] El improvisador debe darse cuenta que mientras más obvio sea, más original parecerá. [...] más obvio sea el improvisador, más auténtico parecerá. [...] Será mucho más creativo cuando aprenda a aceptar la primera idea." (Tradução nossa).

${ }^{10}$ Cada um desses fundamentos propostos por Johnstone está descrito minuciosamente tanto em Muniz (2015), quanto em Maia (2015).
} 
desenvolvimento da história. Por sua vez, a ruptura de uma rotina é um recurso importante para o desenvolvimento da cena e para a manutenção do interesse da improvisação. Essa ruptura pode ser dada de diversas formas, seja por uma reviravolta na história proposta pelos jogadores em cena, seja pela entrada de um novo jogador na cena, propondo uma nova oferta, etc.

Há, ainda, no aprendizado da Impro, procedimentos que objetivam reduzir o tempo entre a ação e a reação do aluno. Ou seja, jogos e exercícios que tem como regra que os jogadores respondam de forma rápida. Desse modo, diante da necessidade de responder rapidamente, o aluno não terá tempo de "escolher" a "melhor" ideia. Esses exercícios são uma preparação para as respostas ágeis na improvisação e a capacidade de perceber diversos estímulos que possibilitem a dramaturgia improvisada, como exemplo: criar a partir de uma frase ouvida do público, de uma imagem vista ou de uma ação de um parceiro em cena.

Para a prática desses procedimentos que lidam sensivelmente com a espontaneidade e a possibilidade do erro como algo natural do processo de aprendizado, é fundamental que a atitude do professor ou diretor seja de acolher, de criar um ambiente solidário e seguro para que o aluno se sinta à vontade em expressar-se. O condutor precisa também, ser sensível às reações dos alunos, pois elas não se pretendem ser autoconsciente.

Por outro lado, a prática do aluno de expressar-se espontaneamente, sem tentar ser original, também permite estar mais conectado com o que já existe de proposta no jogo praticado. Johnstone (2008) chama de círculo de possibilidades a um conjunto de possibilidades que vão se delimitando à medida que a improvisação se desenvolve. Estar atento a esse círculo de possibilidades permite parar de pensar no que deveria ser feito e perceber o que já vem sendo realizado no jogo. É tirar o foco do futuro e colocá-lo no presente e no passado recente. Ao mesmo tempo, é parar de querer ser original e escutar o que já foi feito e, a partir disso, perceber qual é o próximo passo a ser dado.

No processo de ensino-aprendizagem da Impro, os participantes são incitados por Johnstone a se interessarem pelo progresso um do outro e a irem contra o pensamento de uma educação competitiva; ele exprime que, em um grupo, deve-se trabalhar para os demais (Johnstone, 2008). Consideramos essa premissa muito relevante para se praticar Impro, pois ao improvisar o foco do improvisador deve ser perceber, cuidar e instigar o outro em cena. Segundo Madson, "um bom improvisador é uma pessoa desperta, que não é centrada em si mesma, movida pelo desejo de fazer algo útil e generoso e que atua sobre este impulso"11 (Madson, 2013, p. 20).

Como se verá em seguida, O Sistema Impro oferece liberdade ao professor de teatro para encontrar suas próprias práticas de trabalho, exercícios e jogos de improvisação, desde que tais práticas dialoguem com as premissas do sistema de Johnstone: um teatro que trabalhe com a espontaneidade e a imaginação em um ambiente solidário.

11 "Un buen improvisador es una persona despierta, no centrada en sí misma, movida por el deseo de hacer algo útil y generoso y que actúa sobre este impulso." (Tradução nossa). 


\section{A pesquisa da Impro na sala de aula com crianças: como foi investigada?}

Como apresentado, a improvisação definida por Johnstone desenvolve-se pela escuta, atenção, reação e adaptabilidade às diversas ações propostas e é uma prática que prioriza a espontaneidade e a expressão livre de seu praticante. Partindo desse raciocínio, a experiência do Sistema Impro na escola (será apresentada adiante) abarcou uma metodologia de pesquisa que se delineou nessa mesma perspectiva, afinada com premissas do Sistema Impro. Procuramos uma metodologia de pesquisa aberta para se praticar e analisar o Sistema Impro, que fosse passível de mudanças, atenta aos acontecimentos surgidos em processo.

A experiência aprofundada e vivida junto às crianças de idades entre 9 e 11 anos, foi possibilitada pela perspectiva etnográfica ${ }^{12}$ que, em resumo, é um método de pesquisa pertencente ao campo da Antropologia e que se define como a prática do pesquisador inserido em seu campo de pesquisa, sua relação estabelecida de estar junto a, e não sobre o que é investigado (Uriarte, 2012). É um mergulho na realidade que se deseja pesquisar. Dessa forma, a investigação não foi "o Sistema Impro para as crianças", mas, sim, a tentativa diária da professora-pesquisadora em investigar o Sistema Impro com as crianças e junto a elas. Por esse motivo, o presente artigo, a partir deste ponto, segue em primeira pessoa por ser a voz da professora-pesquisadora que esteve em sala de aula com as crianças.

\section{A professora-pesquisadora com as crianças e o Sistema Impro}

A investigação etnográfica realizou-se com discentes do $4^{\circ}$ e $5^{\circ}$ anos de um colégio particular na cidade de Belo Horizonte, na disciplina Teatro inserida na grade curricular da escola para essas turmas. Na ocasião da pesquisa de mestrado, eu era professora nessa escola e trabalhei junto a 17 crianças na turma do $4^{\circ}$ ano e 31 crianças na turma de 5 ano, todas com idades entre 9 e 11 anos. Como foi uma investigação do Sistema Impro com as crianças, foi de fundamental importância iniciar o entendimento do universo da criança em uma perspectiva sociológica e que houvesse a reflexão sobre a posição da criança na pesquisa acadêmica, se ela é ouvida ou se é vista somente pelo olhar do adulto. Procurei saber da própria criança qual a sua relação com a experiência da Impro e tive iniciada uma noção de infância e o processo de ampliação, gradativo, de meu olhar diante a criança.

Clifford Geertz (1926-2006), renomado antropólogo estadunidense, evidenciou que etnografar "não é estudar as aldeias, mas estudar nas aldeias" (1973, p.16, grifo do autor). Sua afirmação possibilitou-me refletir que meu olhar de professora não poderia mais ser o de quem vê de fora e analisa, mas um olhar de pesquisadora-docente que procura estar "dentro" e inserida no campo pesquisado. Eu, pesquisadora, que observou e conviveu com o "objeto" estudado: o Sistema Impro e o aprendizado teatral dos meus alunos em sala de aula.

A partir dessa reflexão embasada pelo pensamento de Geertz (1973) e Uriarte (2012), a pesquisa realizada filiou-se à ideia de pessoas e suas singularidades, não

\footnotetext{
${ }^{12} \mathrm{O}$ método etnográfico foi-nos apresentado pela coorientadora da dissertação, a Profa. Dra. Marina Marcondes Machado.
} 
de sujeitos vistos de maneira generalizada. Mais especificamente, de crianças (quais, quantas, como se comportam) fazendo teatro com a prática do Sistema Impro: "É nisso que consiste o cerne do método etnográfico: em trabalhar com pessoas, [...] ver pessoas, não indivíduos, pessoas com nomes, com posições, detentores de palavra, de saber" (Uriarte, 2012, p.5-6).

Cativada pela perspectiva de estar com e não sobre o objeto ou o sujeito estudado, como evidenciam as práticas da etnografia e da pesquisa-ação ${ }^{13}$, apropriei-me, então, da ideia de trabalhar o teatro $\mathrm{com}^{14}$ as crianças e não para as crianças.

A pesquisa etnográfica teve seu registro na confecção do Diário de Pesquisa: "instrumento para trabalhar as implicações do professor, do pesquisador" (Barbosa; Hess, 2010, p. 78). A ação de estar junto do objeto a ser pesquisado demanda do pesquisador a habilidade de escrever uma descrição detalhada de tudo o que observou, percebeu, compreendeu, questionou. Minhas descrições dedicavam-se a relatar como as crianças estavam, como se comportavam em cada aula e em cada exercício ou jogo de Impro ${ }^{15}$ praticado, suas feições, reações e dizeres. O que diziam suas corporalidades? Como e quando elas estavam aprendendo a Impro? O processo etnográfico é intrínseco à atitude de manter um diário e nele anotar, detalhadamente, uma "descrição densa"16 de tudo o que é vivido em pesquisa.

A prática do Diário de Pesquisa foi para mim o propulsor de reflexão e aprofundamento do conhecimento do exercício docente, como: maior percepção de todo o acontecimento de lecionar (ambiente, alunos, contexto, problemas disciplinares e didáticos, conteúdo, etc.); a educação e o teatro aos quais me vinculo, acredito e exerço; a percepção dos dizeres dos alunos pelas suas ações, feições e engajamento nas atividades. Tais questões foram levantadas e refletidas pela escrita no diário. Por percebê-lo como parte importante no processo de ensino-aprendizagem, fiquei instigada em propor aos alunos que eles também mantivessem um Diário de Bordo ${ }^{17}$ das nossas aulas de Teatro. Meu objetivo inicial era tentar estimular nos alunos uma pequena reflexão sobre cada aula vivenciada, de modo que eu tivesse um registro escrito (ou desenhado, pois em muitas páginas as crianças se expressaram por desenhos) do aprendizado da improvisação, pela perspectiva dos próprios alunos.

O diário foi mantido pelas crianças de forma coletiva, a cada aula era sorteado, dentre os que gostariam de levá-lo para casa, o aluno que registraria o que quisesse e da forma que quisesse as impressões daquela aula vivenciada. A elaboração dos diários das turmas trouxe-me a expectativa sobre as percepções advindas das crianças mesmas sobre as aulas, em uma tentativa de dar voz e ouvir suas ideias de uma maneira mais livre e informal. A estratégia descoberta de promover também às crianças os diários de bordo, para que elas mesmas pudessem registrar o que elas aprendiam diariamente do Sistema Impro, foi ao encontro da perspectiva sociológica da infância de ver, ouvir e saber da criança por ela mesma ${ }^{18}$.

\footnotetext{
${ }^{13}$ Conceito de René Barbier (2007) que, de forma resumida, é o pesquisador que está inserido em seu campo de pesquisa, ele está com o seu objeto, pesquisando em ação.

${ }^{14}$ A reflexão de fazer teatro com as crianças e não para elas, partiu da leitura do artigo: "Teatro e Infância, em busca da poética do devir", de Sidmar Silveira Gomes (2014).

${ }^{15}$ Adiante, na parte de análise da prática do Sistema Impro com as crianças, serão descritos, em resumo, os exercícios praticados na pesquisa compartilhados neste artigo.

${ }^{16}$ Expressão de Clifford Geertz (1973).

${ }^{17}$ A reflexão e proposta para que os alunos também mantivessem um diário, partiu da leitura do artigo: "O Diário de Bordo como ferramenta fenomenológica para o pesquisador em artes cênicas", de Marina Marcondes Machado (2002).

${ }^{18}$ Embasamo-nos nas ideias da Sociologia da Infância a partir das leituras de Sirota (2001), Kohan (2007) e Belloni (2009).
} 


\section{Da criação das categorias de análise dos diários às analises: saber da criança mesma a sua experiência com a Impro}

Para que fosse possível ler, analisar e compartilhar toda essa experiência de ensino e aprendizagem do Sistema Impro com os alunos, o processo posterior às aulas ministradas foi o da leitura e releitura atenta e detalhada tanto dos diários da professora, quanto o dos alunos, a fim de permitir que descobertas e vivências impressas em todo o material etnografado aparecessem. Sobre esse trabalho delicado de criar categorias de análise a partir dos diários, destaca-se este fragmento da dissertação oriunda dessa experiência.

Apresento os registros materiais da prática e da experiência, o que me requereu o esforço da síntese e de saber o que relevar: a prática etnográfica que foi programada, organizada, planejada; e a experiência etnográfica vivida, imprevista, alterada e, às vezes, bagunçada. Desafio-me a apresentar os registros imateriais dessa prática, o que me requereu o esforço de aprofundar-me em minha poética própria e no aprendizado da capacidade de ler o outro para analisar a experiência vivida, sentida, apreendida, e a tentativa de mapear os momentos de aprendizado. Os momentos de frustrações e insights, as angústias e dificuldades, as superações, a felicidade, o aprendizado (tanto meu, mas principalmente dos alunos) encontram nos diários - nas palavras e nos desenhos - uma tentativa de expressão que se materializa. Entretanto, esse registro material não consegue abarcar todos os momentos da experiência, que ficam no registro da memória, na recordação, no corpo. (Maia, 2015, p.65-66)

Esse momento da releitura dos registros resultou na criação de categorias de análise. Por uma escolha didática e metodológica, foram enumeradas em quatro e intitularam-se em: "cara-e-corpo", "criatividade", "criação em parceria" e "cenas improvisadas".

O desafio foi o de criar categorias que se originassem das premissas da improvisação de Keith Johnstone em diálogo com as experiências advindas da sala de aula com as crianças, para que pudesse ser feita a leitura, interpretação e análise da sequência didática das aulas de etnografadas.

As categorias explicitaram os momentos de ensino e aprendizado do Teatro por intermédio do Sistema Impro, em que foram vivenciados pelos alunos processos de estímulo à criatividade, ao trabalho corporal pela definição "cara-e-corpo", à criação teatral em parceria e à experiência das cenas improvisadas.

A categoria "criatividade" foi escolhida pelo fato de a proposta de ensino-aprendizagem da improvisação de Keith Johnstone ter a criatividade como a propulsora e a motivação de sua criação.

"Cara-e-corpo" definiu-se como a categoria do aprendizado das crianças em "fazer-se de outros", trabalhar com suas possibilidades corporais para fazerem, nos seus corpos, objetos, personagens, expressar sentimentos ou sensações. O surgimento dessa expressão na vivência do Sistema com as crianças emergiu do processo de trabalhos corporais distintos do cotidiano dos alunos, que objetivaram estimular neles a percepção de elementos teatrais possíveis para a criação das cenas improvi-

\footnotetext{
${ }^{9}$ Brown also collaborated with multimedia, film and video artists, including Robert Whtiman on Homemade (1966), Jud Yalkut on Planes (1969) and Babette Mangolte, who documented Roof and Fire Piece (1973). (Tradução nossa)

${ }^{10}$ Because of the dance's sheer bravado and speed I also felt that the physical abilities of the dancer had to be so fine-tuned that maybe Trisha would not be able to dance it for many years to come and therefore the film recording of it was urgent and should not be delayed. Although Trisha laughed at my fear that she was not going to be able to perform it for many more years she agreed that I could film it. (Tradução nossa)
} 
sadas.

A categoria seguinte relaciona-se à uma das condições prementes da Impro: a aceitação da ideia proposta pelo outro (para que possa ser iniciada e construída uma história inventada por dois, três ou mais alunos). Diante disso, a expressão "criação em parceria" era verbalizada por mim no momento de instruir os alunos, ou orientá -los, na criação teatral improvisada.

Por fim, a "cenas improvisadas": a categoria que propiciou a análise e reflexão da ação de se improvisar uma cena junto ao outro e diante do público. Criar essa categoria gerou as perguntas: em que momentos e de que maneira os alunos vivenciaram a prática de improvisar uma cena teatral? Como e o que eles improvisaram?

Todas essas categorias se articularam almejando entretecer as questões motivadoras da pesquisa sobre o Sistema Impro e suas possibilidades no ensino do Teatro com crianças na escola e a ampliação dos conhecimentos dessa prática, para além do universo dos atores-improvisadores, mas para a pedagogia teatrol e teatro com crianças.

Apresentamos alguns trechos de registros e uma possível leitura interpretativa da prática etnográfica do Sistema Impro com crianças, recortes e interpretações dos diários, tanto do diário de pesquisa que aborda cada aula ministrada pela professora-pesquisadora, quanto do diário de bordo confeccionado pelas próprias crianças das aulas experienciadas por elas. Foram mapeados trechos que elucidam a prática em sala de aula a partir das categorias escolhidas para a análise dessa experiência: a "cena improvisada", "criatividade", "cara-e-corpo" e "criação em parceria".

O desafio foi o de criar categorias que se originassem das premissas da improvisação de Keith Johnstone em diálogo com as experiências advindas da sala de aula com as crianças, para que pudesse ser feita a leitura, interpretação e análise da sequência didática das aulas de etnografadas.

As categorias explicitaram os momentos de ensino e aprendizado do Teatro por intermédio do Sistema Impro, em que foram vivenciados pelos alunos processos de estímulo à criatividade, ao trabalho corporal pela definição "cara-e-corpo", à criação teatral em parceria e à experiência das cenas improvisadas.

A categoria "criatividade" foi escolhida pelo fato de a proposta de ensino-aprendizagem da improvisação de Keith Johnstone ter a criatividade como a propulsora e a motivação de sua criação.

"Cara-e-corpo" definiu-se como a categoria do aprendizado das crianças em "fazer-se de outros", trabalhar com suas possibilidades corporais para fazerem, nos seus corpos, objetos, personagens, expressar sentimentos ou sensações. O surgimento dessa expressão na vivência do Sistema com as crianças emergiu do processo de trabalhos corporais distintos do cotidiano dos alunos, que objetivaram estimular neles a percepção de elementos teatrais possíveis para a criação das cenas improvisadas.

A categoria seguinte relaciona-se à uma das condições prementes da Impro: a aceitação da ideia proposta pelo outro (para que possa ser iniciada e construída uma história inventada por dois, três ou mais alunos). Diante disso, a expressão "criação em parceria" era verbalizada por mim no momento de instruir os alunos, ou orientá -los, na criação teatral improvisada.

Por fim, a "cenas improvisadas": a categoria que propiciou a análise e reflexão da ação de se improvisar uma cena junto ao outro e diante do público. Criar essa categoria gerou as perguntas: em que momentos e de que maneira os alunos vivenciaram 
a prática de improvisar uma cena teatral? Como e o que eles improvisaram?

Todas essas categorias se articularam almejando entretecer as questões motivadoras da pesquisa sobre o Sistema Impro e suas possibilidades no ensino do Teatro com crianças na escola e a ampliação dos conhecimentos dessa prática, para além do universo dos atores-improvisadores, mas para a pedagogia teatrol e teatro com crianças.

Apresentamos alguns trechos de registros e uma possível leitura interpretativa da prática etnográfica do Sistema Impro com crianças, recortes e interpretações dos diários, tanto do diário de pesquisa que aborda cada aula ministrada pela professora-pesquisadora, quanto do diário de bordo confeccionado pelas próprias crianças das aulas experienciadas por elas. Foram mapeados trechos que elucidam a prática em sala de aula a partir das categorias escolhidas para a análise dessa experiência: a "cena improvisada", "criatividade", "cara-e-corpo" e "criação em parceria".

Compartilhamos, a seguir, neste artigo, alguns registros dessa experiência do trabalho de campo, as dificuldades, inspirações e aprendizados dessa investigação.

Abaixo, segue um trecho de uma aula registrada no diário da pesquisadora (que fora transcrito para a dissertação), já com os recortes de sua posterior análise:

$5^{\circ}$ ano, no dia 29 de outubro de 2014, quarta-feira. Dessa vez com o "Jogo do Presente", que também tem, em si, o objetivo de exercitar a criação de ofertas.

Pessoal, vamos fazer uma roda. A gente vai fazer o "Jogo do Presente". Uma pessoa da roda vai se deslocar em direção a um colega para presenteá-lo, estará com as mãos em concha, e nelas estará um presente imaginário. Em seguida, o aluno que recebeu o presente vai nos mostrar qual foi o primeiro presente que passou pela sua cabeça em ganhar. Ou seja, quem ganha o presente é que escolhe e define o que ganhou. Atenção, mostre a primeira imagem de presente que vier na sua cabeça! O presente é seu, você o escolheu, pode ser o que você quiser. Tente não dizer o que você ganhou, mas nos mostrar o que é o presente imaginado por você pela sua forma de interação com ele. Exemplo: não diga "Oh, que livro legal!", mas nos mostre que é um livro pela maneira como você pega e manuseia este objeto, como você o usa, sua reação ao recebê-lo, etc. Descubra como nos mostrar o presente que você mesmo escolheu pra você!

[...] Desde seu início, estavam todos atentos tentando descobrir qual o presente imaginado pelo colega. De maneira generalizada entre os alunos, eram olhares atentos, comentários sobre o que poderia ser o presente, alguns pulavam ansiosos. Simultaneamente à empolgação em descobrir o que o outro ganhava e a demora para que todos jogassem e fossem presenteados, teve início um burburinho entre alguns alunos: Me entrega o presente? Eu quero ir!

\section{EU, EU!! Me dá mresente: Me escollhe? Até agoha cu nãofhe! 19}

Eram diversos alunos dizendo essas frases a cada rodada do jogo. A fim de deixar a atividade mais dinâmica e não deixar que os alunos perdessem o interesse em jogá-lo, decidi, então, separar a turma em dois grupos para que todos pudessem ser presenteados mais rapidamente. Um grupo ficaria dentro da sala e o outro no nosso pequeno quintal interligado à sala.

[...] Foi muito interessante observar a maneira de as crianças realizarem as ações de presentear e de serem presenteadas. Estavam atentos uns aos outros jogando. O mais interessante do jogo passou a ser a descoberta do presente. Alguns alunos, como o $\mathrm{PE}^{20}, \mathrm{MA}, \mathrm{DE}, \mathrm{GO}$, e as meninas DA, VA e RI, começaram a se

\footnotetext{
${ }^{19} \mathrm{~A}$ fonte e tamanho das letras são diferentes do restante do texto propositalmente, a fim de elucidar que nesse momento se trata das vozes das crianças, além de dar a entender que eram dizeres de crianças distintas.

${ }^{20} \mathrm{Na}$ dissertação da qual se origina este artigo, os alunos e alunas foram apresentados e identificados somente por sílabas, a fim de preservarmos suas identidades.
} 
dedicar a tentar adivinhar qual era o presente que o presenteado escolhia, como se estivessem em um jogo de mímica. Com isso, surgiu-me o receio de as crianças perderem o foco do exercício, que era o de mostrar corporalmente a primeira imagem de presente imaginada, e passarem a focar em tentar adivinhar o que era o presente, pois começaram a gritar: í uma caixa: Uma máquina! Um cofre? [..] (Maia, 2015, p. 82-84).

Abaixo, partilhamos trechos dos diários dos alunos sobre a mesma aula descrita e apresentada anteriormente sob a perspectiva da professora-pesquisadora. $O$ registro que se segue foi realizado no diário da turma de $5^{\circ}$ ano pelo aluno MA sobre a aula do dia 29 de outubro de 2014. O desenho é um bom exemplo do que se tornou o "Jogo do Presente" em algumas rodadas: um jogo de adivinhação.

Adivinhe logo qual o presente que estou imaginando... Looooogo!!! Pois é pesado... ${ }^{21}$

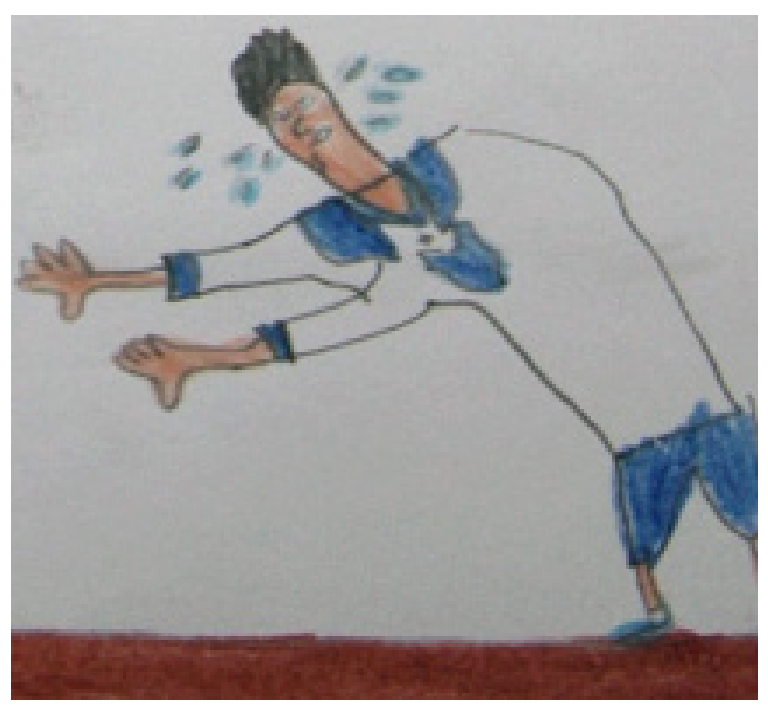

${ }^{21}$ Os diálogos presentes no desenho do aluno já são a leitura e análise que realizamos dos diários das crianças. 


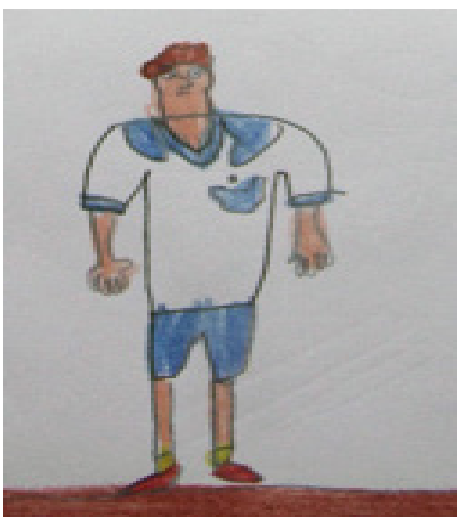

Hum... Não sei...

O que é????

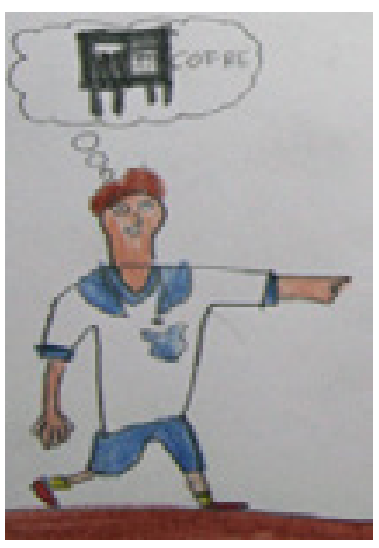

Já sei!!!

Um cofre!!

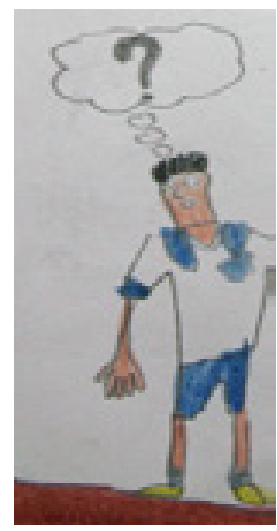

Am??

FIGURA 1 - Isso não é um cofre

Ao deparar-me com esses desenhos criados por um de meus alunos, como forma de expressar sua percepção das nossas aulas de Impro, pude analisar seu registro visual da seguinte forma:

O aluno de cabelos pretos está suando diante do esforço de carregar seu presente imaginado, seu tronco está inclinado para frente e seus braços estendidos parecem estar tensionados carregando algo; o desenho transmite a sensação de movimento. O colega de cabelos avermelhados olha-o sem entender bem o que pode ser o presente, seus lábios estão retos, seu olhar atento, ele está estático. Porém, na imagem seguinte, ele parece ter tido uma ideia do que poder ser: um cofre! Seus olhos e boca sorriem; suas pernas já se movem; seu braço esquerdo em direção ao colega e o dedo indicador apontado, é como se dissesse: É isso!! MA desenha um cofre em seu "balão" detalhadamente, há até dinheiro lá dentro. Mas, ele coloca a palavra cofre dentro do "balão", que remete a pensamento, e não à palavra dita ao outro. Por quê? A reação do aluno que levava o presente pesado possibilita a interpretação de que não era um cofre que ele imaginara: seus olhos arregalados e sua boca levemente aberta e séria; em seu "balão" está desenhada uma interrogação. Os rostos dos meninos desenhados, seus olhares e movimentos da boca explicitam seus sentimentos com clareza. (Maia, 2015, p.127) 

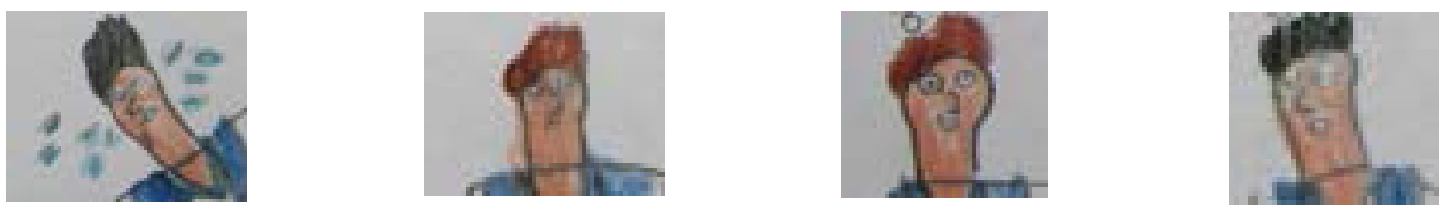

FIGURA 2 - Detalhes dos rostos dos meninos

Os corpos, a intenção dos braços, a inclinação da coluna presentes nos meninos desenhados por MA, são, aparentemente, uma tentativa de mostrar pelo corpo e não pela palavra qual presente tinha imaginado ganhar. Essa observação remeteu-me diretamente aos corpos dos meus alunos ao fazerem o jogo de improvisação em sala de aula naquele dia. A partir da concretude do discurso dos meus alunos - os desenhos e os textos - desenvolvemos as reflexões e análises da relação e aprendizado das crianças com a Impro sob o ponto de vista delas mesmas.

A pesquisa etnográfica que me permitiu "dizer o que vi" ao fazer o exercício de relatar minuciosamente cada dia de experiência em meio às crianças praticando o teatro, culminou nas possibilidades interpretativas dessa experiência, operando reflexões, sentidos, remetimentos e, sobretudo, indagações. Pois, o olhar em uma pesquisa etnográfica preocupa-se mais em gerar reflexões e questionamentos que respostas definitivas. Ao ler os registros de meus alunos, também me permiti à alusão de outras ideias, à minha própria infância, à criação de imagens a partir das imagens das crianças, trazendo, no "resultado" da pesquisa e nas análises dos registros dos meus alunos, uma metalinguagem da premissa de associação livre da Impro.

Como essa prática dos diários dos alunos foi uma abordagem e experimentação pedagógica e metodológica inovadora em meu percurso docente e de iniciante à pesquisa, ter tido a experiência de ver muitos dos registros dos alunos feitos por desenhos, despertou-me para uma nova forma de perceber essas crianças já "crescidas" de 9 a 11 anos de idade. Percebê-los envolvidos pela ação de desenhar como maneira de reflexão da realidade vivida, levou-me a querer entender melhor sobre a relação criança e desenho. E, para melhor poder ver e interpretar seus desenhos, dediqueime às leituras que tivessem por temática o desenho da criança e pesquisas teatrais que tinham, como sujeitos, crianças. ${ }^{22}$

Percebi, pelos desenhos dos meus alunos, que o ato de desenhar da criança é uma forma de linguagem e de expressão, assim como a fala e o gesto. Debrucei-me diante dos desenhos e palavras textuais dos meus alunos. A seguir, apresentamos o texto que MA escreveu no diário junto ao desenho:

Na minha aula de teatro, fizemos uma brincadeira que exercita a imaginação das crianças. Fizemos duas rodas, uma de meninos e outra de meninas ${ }^{23}$. A gente tinha que "presentiar" uma pessoa com qualquer coisa, mas para a pessoa saber o que ela ganhou, a pessoa que presentiou deveria mostrar o formato e o peso da tal coisa usando a imaginação. E quem presentiado faz a mímica do que recebeu

\footnotetext{
${ }^{22}$ Como, por exemplo, o livro de Ana Angélica Albano, O Espaço do Desenho: A Educação do Educador (2013), que se tornou meu livro de referência em minha ação de ver e ler os desenhos dos meus alunos, e Thais Ferreira, com seu livro A Escola no Teatro e o Teatro na Escola (2006).

${ }^{23}$ A divisão das duas rodas entre os gêneros não foi intencional, foi algo ocasional no momento da aula por uma simples questão espacial e de dinamicidade na divisão no momento do jogo. Eram muitos alunos para uma roda só, o que estava interferindo no interesse deles pelo jogo. Em uma reação rápida, com o jogo em curso, pelo número de meninos ser maior, orientei a eles que permanecessem na sala de aula em uma roda, e que as meninas fizessem uma segunda roda na parte externa da sala, no pequeno quintal que tínhamos acoplado à sala. A sala tinha o espaço maior que o pequeno quintal.
} 
e depois presenteia outra pessoa. (Sic).

(MA, Diário de Bordo das crianças do $5^{\circ}$ ano, dia 29/10/14)

No texto escrito, o aluno MA evidencia que nossa prática daquela aula tinha por maior objetivo o estímulo à imaginação deles. Ele descreve exatamente o que foi nossa atividade. Como foi possível ver na parte introdutória deste artigo, Johnstone (2008) tem por uma das bases de seu trabalho para a improvisação a liberação da imaginação. Assim, analisar o desenho e o texto do aluno MA me proporcionaram a reflexão de que a realização desse jogo pertencente à prática da Impro foi interessante e enriquecedora para ele.

Por sua vez, o registro realizado pela aluna $\mathrm{Fl}$, eluci dado no desenho a seguir, possibilitou a análise de que a Impro propõe que o jogador esteja aberto e atento às coisas que o circundam, permitindo expressar-se por associação de ideias. Este é o repertório para as improvisações: você mesmo (suas vivências, seu conhecimento, suas inspirações).

O desenho de $\mathrm{Fl}$, associado à minha observação de sua ação ao fazer o jogo em sala de aula nesse dia (pelos registros do meu diário), permite-me a análise de que ela realizava com interesse e curiosidade a ação de inspirar-se e ter por estímulo e oferta para a criação da improvisação, diante da observação, a corporalidade do outro. Nomeei seu registro de "Os três olhares":

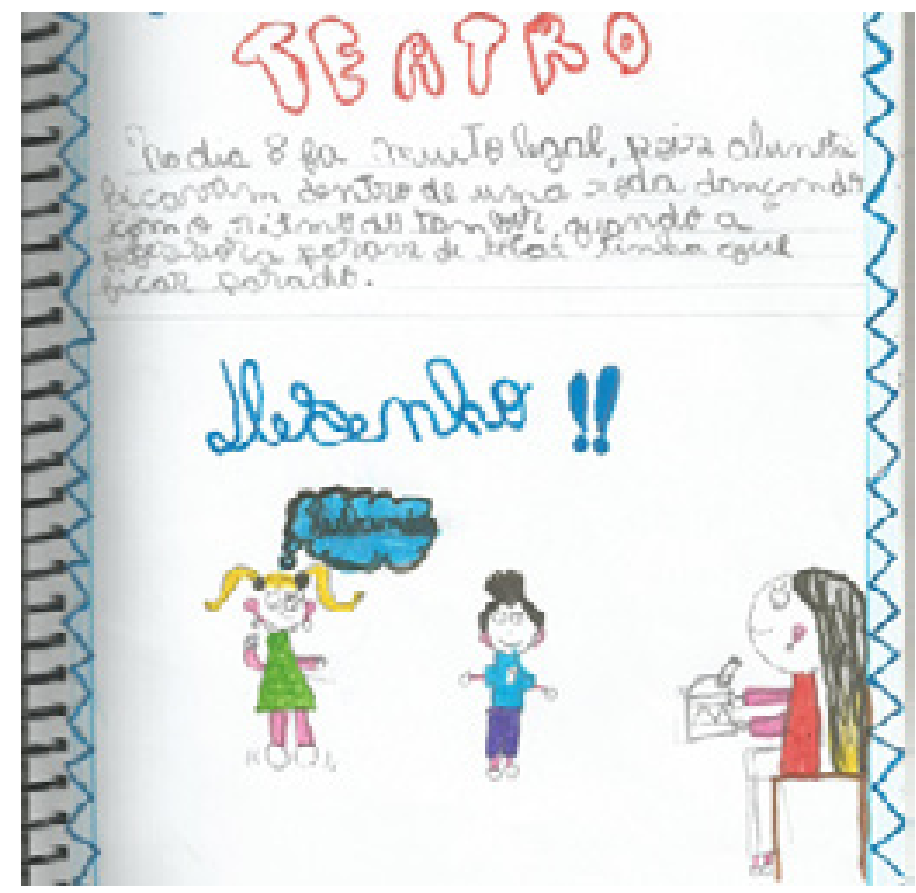

FIGURA 3 - Registro do Diário de Bordo em 8 de outubro de 2014, feito pela aluna FI, do $5^{\circ}$ ano, da prática do jogo "Posição-imagem"

Transcreve-se, aqui, parte da análise feita na dissertação a partir desse desenho:

No desenho vemos duas crianças com suas roupas coloridas. A menina tem um balão acima da cabeça onde está escrito que ela está pulando, seus braços voltados para cima associados à imagem dos pequenos traços que ela desenhou embaixo de seus pés também explicitam sua ação de pular. O menino, com sua roupa azul e uma pequena parte branca em sua blusa, me remete ao uniforme da escola. Ele parece estar no momento da "posição-imagem", pois me transmite a ideia de estar 
parado, porém não relaxado, como se estive em ação, já que seus braços estão perpendiculares e não paralelos e descansados ao longo do corpo. À direita, sentada na cadeira com um tambor na mão, leio que seja um desenho meu: o tambor que uso nas aulas, os cabelos compridos com pontas claras, o fato de estar sentada na cadeira nesse momento do jogo. Ambos me olham e eu também olho para eles. [...] Eles parecem atentos ao meu comando. Interessados pela prática que mesclava movimento e som, criação de histórias a partir das imagens corporais e a observação de si e do outro.

O traço de todo o desenho de FI, o desenho dos olhos (bem redondos e com três cílios destacados), o uso de canetinhas coloridas, a maneira de desenhar os corpos dos "personagens" e sua forma de escrever com suas letras grandes e um pouco tortuosas acrescidas da margem no papel feita por ela, aludem-me, de uma maneira especial, às formas de expressão das infâncias que conheço: a minha e de meus pares e a dos meus alunos.

(Maia, 2015, p.136-137).

Cada registro dos alunos, no Diário de Bordo da turma, apresentou-me, de maneira instigante, curiosa e inédita, sua forma de expressarem suas vivências em nossas aulas. Os diários das crianças estão entre as descobertas mais importantes no processo do que foi a pesquisa, as possíveis conclusões dessa experiência de aprendizado sobre o teatro e do estímulo da criatividade dos alunos provêm deles mesmos. Seus diários, somados aos meus relatos de suas corporalidades em sala de aula, suas maneiras de se relacionarem com a Impro, com o outro e comigo, levaram-me à conclusão do processo investigativo da Impro como possibilidade ensino do Teatro às crianças.

Ao longo do processo etnográfico nas aulas de teatro, pude notar os momentos de criação teatral pelas crianças embasados nas premissas e conceitos do sistema de aprendizado da improvisação teatral como espetáculo de Johnstone. Especialmente, ressalto a premissa de estar ali para ajudar o outro, criando em parceria, expondo suas ideias, e os conceitos de escuta, de associação livre, de propor ofertas e de brincar com as reações de status em cena. Infiro que as crianças puderam ter, com essa experiência, descobertas - sobre suas capacidades criativas, sobre a possibilidade de estar em cena criando junto com o colega uma história improvisada-, e o aprendizado do fazer teatral por meio dessa metodologia da Impro: um teatro que tem por premissa a prática do improviso pelo aluno/jogador tanto na sala de trabalho quanto no "palco". Assim, por essa pesquisa da Impro ter se dado com crianças, temos assim um fazer teatral que parte das ideias imaginadas pelas crianças mesmas.

Ao fim da pesquisa de mestrado, estava tomada pela sensação de ter vivenciado o fazer de uma pesquisa permeada por descobertas, encontros e memórias. Descobertas que foram além das almejadas: uma nova maneira de perceber e relacionarme com meus alunos e um fazer teatral genuíno da prática da Impro com as crianças. Encontros que construíram, gradualmente, a tríade eu - as crianças - o Sistema Impro, pelas memórias materiais, registradas nos diários, e as imateriais, registradas na minha maneira de estar e relacionar-me com o mundo: o mundo da docência com crianças, o mundo de fazer teatro com as crianças. Tais descobertas, encontros e memórias, possibilitadas pela etnografia detalhada e refletida de cada momento da investigação, foram principiados pelo desejo de analisar o Sistema Impro no processo de ensino-aprendizagem do teatro de alunos na escola.

\footnotetext{
${ }^{19}$ Fonte: https://www.moma.org/learn/moma_learning/carolee-schneemann-up-to-and-including-her-limits-1973-76. Acesso em: 17 nov. 2017.
} 


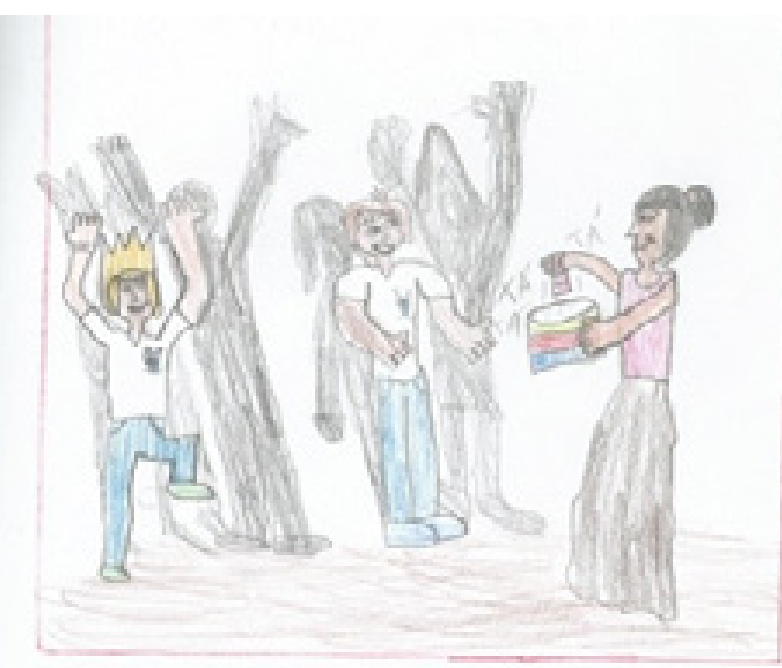

FIGURA 4 - Eu - as crianças - o Sistema Impro

DE, Diário de Bordo do $5^{\circ}$ ano, 2 de dezembro de 2014

Esse desenho, que se refere às nossas práticas da improvisação teatral em sala de aula, foi realizado pelo aluno DE no diário de bordo da turma. As feições e corporalidades impressas no desenho, as minhas e as dos alunos, mostram-nos a relação e a recepção das crianças à prática daquele momento: o Sistema Impro. Assim, configurei o que nomeamos de tríade, formada por eu - as crianças - o Sistema Impro. Esse desenho pode ser entendido como símbolo dessa formação, desse encontro.

Essa tríade, que, simultaneamente, fora construída durante o processo das aulas etnografadas e balizou a pesquisa, sintetiza a investigação desenvolvida: a professora e sua poética própria, sua biografia e sua maneira de pensar e fazer teatro; as crianças - meus alunos de 9 a 11 anos, discentes do cotidiano que me instigaram ao exercício de colocar-me junto a eles e ouvi-los fazer e aprender o teatro improvisado de Johnstone, saber de suas ideias, suas dúvidas, descobrir seus desenhos e formas de se expressarem; e o Sistema Impro, a prática teatral que fundamentou a pesquisa e fundamenta meus fazeres docentes, artísticos, cotidianos e, como vimos, pode ensinar Teatro às crianças.

A experiência vivida, neste artigo resumidamente relatada, faz-nos constatar que a pesquisa realizada poderá contribuir, de maneira efetiva, para a ampliação do conhecimento sobre o Sistema Impro e a possibilidade de encontrarmos na proposta de improvisação de Keith Johnstone uma prática para o ensino teatral na escola.

O Sistema Impro na sala de aula: uma expectativa de difusão dessa possibilidade educacional no teatro

Podemos perceber, na experiência descrita, que o Sistema Impro permitiu ensinar elementos da linguagem teatral, tais como: jogo cênico, personagens, narração, dramaturgia, estéticas cênicas e a capacidade de improvisar em grupo; todos eles entremeados nas observações e descritos por meio das categorias de análise abordadas: "cara-e-corpo", "criatividade", "criação em parceria" e "cenas improvisadas".

Os exercícios praticados em sala de aula tiveram origens diversas, muitos foram selecionados a partir de experiências nossas com grupos de Impro de diversos países, 
outros foram criados por nós ou adaptados de brincadeiras de roda e jogos de regra. Assim o fizemos porque acreditamos que a função do professor de teatro é criativa e que as referências teóricas, metodológicas e artísticas devem inspirar o desenvolvimento de um percurso próprio.

Nós, professoras de improvisação, pensamos que ministrar uma aula de improvisação (embora se tenha um planejamento como em qualquer outra proposta metodológica), é improvisar também, pois precisamos perceber como o outro está (o aluno) e lançar uma proposta a partir dessa leitura. Destacamos hoje, pela experiência com o teatro na sala de aula da escola de ensino básico, que uma das características mais importantes de um professor é a capacidade de perceber o que propor a cada momento da aula. Muitas vezes, uma estratégia de aula planejada anteriormente precisa ser totalmente reconfigurada diante da recepção, da postura, interação e desejos expressos pelos alunos. O Sistema Impro ajudou-nos nessas percepções dos alunos, pois a escuta também se faz fundamental à prática do professor.

A experiência de praticar a improvisação de Johnstone com crianças nos fez perceber a possibilidade criativa que essa prática pode proporcionar ao fazer teatral dos alunos na escola e o estimulo à sua imaginação. Percebemos, especialmente, às possibilidades de ensino-aprendizagem que o Sistema Impro pode oferecer ao aprendizado do teatro no Ensino Fundamental. Somadas a isso, a abordagem em sala de aula de permitir aos alunos expressarem sua primeira ideia sem temer o erro, atitudes intrínsecas à prática da Impro, podem contribuir para a construção de sua confiança, possibilitando à criança perceber-se criativa espontaneamente, quando por exemplo, ela mostra e faz entender ao outro, improvisadamente (com seu corpo, reações e interações com um objeto imaginário), qual é o presente que the veio à cabeça sem tempo de preparação, como vimos em uma das práticas aqui relatadas dos diários dos alunos.

Encontramos, na pedagogia do Sistema Impro, tanto a possibilidade de ensino do Teatro e da improvisação em si como linguagem teatral, quanto, também, uma facilitadora no aprendizado de outras metodologias do ensino do Teatro. Pensamos isso, devido a prática da Impro apresentar propostas, jogos e possibilidades para o trabalho com a criatividade, escuta e atenção com o outro em cena, conteúdos essenciais em qualquer atividade ou metodologia teatral escolhida pelo professor e levada à sala de aula.

Desejamos que este artigo estimule a outros professores a conhecer esse Sistema e desenvolver suas próprias metodologias.

\section{Referências}

ACHATKIN, Vera Cecília. O Teatro-esporte de Keith Johnstone e o ator: da ideia à ação - A improvisação como instrumento de transformação para além do palco. 148 f. Dissertação (Mestrado em Artes) - Escola de Comunicação e Artes, Universidade de São Paulo, São Paulo, 2005.

ALBANO, Ana Angélica. O espaço do desenho: A educação do educador. 16 ed. São Paulo: Edições Loyola, 2013. 
BARBOSA, Joaquim Gonçalves; HESS, Remi. O diário de pesquisa: o estudante universitário e seu processo formativo. Brasília: Liber Livros, 2010.

BELLONI, Maria Luiza. O que é a sociologia da Infância. Campinas, SP: Autores Associados, 2009.

Diário de Bordo das crianças do $4^{\circ}$ e $5^{\circ}$ ano, 2014. Manuscrito.

DUDECK, Theresa Robbins. Keith Johnstone: A Critical Biography. London: Bloomsbury Methuen Drama, 2013.

FERREIRA. Taís. A escola no Teatro e o teatro na escola. 1a ed. Porto Alegre: Mediação, 2006.

GEERTZ, Clifford. A interpretação das culturas. Rio de Janeiro: Zahar, 1973.

GOMES, Sidmar Silveira. Sociologia da Infância e Jogos Teatrais: territórios de uma pedagogia teatral. Revista Aspas, Ppcag USP. v.4, p. 58-67, 2014.

JOHNSTONE, Keith. IMPRO: Improvisation and the theater. New York: Penguin Books, 1979.

IMPRO. Improvisación y el teatro. 5. ed. Santiago do Chile:

Editorial Cuatro Vientos, 2008.

Impro for Storytellers. New York: Routledge, 1998.

KASTRUP, Virgínia. A invenção de si e do mundo: Uma introdução do tempo e do coletivo no estudo da cognição. Belo Horizonte: Autêntica, 2007

KOHAN, Walter. O. Infância, estrangeiridade e ignorância. Belo Horizonte: Autêntica, 2007.

MACHADO, Marina Marcondes. O Diário de Bordo como ferramenta fenomenológica para o pesquisador em artes cênicas. Revista Sala Preta [online]. v.2, p.260 - 263, 2002.

MADSON, Patricia Ryan. La Sabiduría de la Improvisación. México: Teatrika, 2013.

MAIA, Hortência. Sistema Impro com crianças: experiência de ensino- aprendizagem do teatro na educação fundamental. 163 f. Dissertação (Mestrado em Artes) - Universidade Federal de Minas Gerais, Escola de Belas Artes, 2015

MUNIZ, Mariana Lima. Improvisação como espetáculo: Processo de criação e metodologias de treinamento do ator-improvisador. 1ํㅗ ed. Belo Horizonte: Editora UFMG, 2015. 
. Diário de Bordo: formação com Keith Johnstone. Calgary (CA), 2014. Material inédito.

; MAIA, Hortência Campos. Sistema Impro: uma prática em desenvolvimento no ensino de teatro na educação básica. In CONGRESSO DA ASSOCIAÇÃO BRASILEIRA DE PESQUISA E PÓS-GRADUAÇÃO EM ARTES CÊNCIAS, VIII, 2014, Belo Horizonte. Anais. Disponível em: http://portalabrace.org/viiicongresso/resumos/pedagogia/ MUNIZ\%20Mariana\%20Lima.pdf Acesso em: 03 maio 2017.

NACHMANOVITCH, Stephen. Ser criativo: O poder da improvisação na vida e na arte. 5.ed. São Paulo: Summus, 1993.

SANTOS, José Luís Alonso. La Escritura Dramática. Madrid: Editorial Castália, 1999.

SIROTA, Régine. Emergência de uma sociologia da Infância: evolução do objeto e do olhar. Cadernos de Pesquisa, no 112, p.7-31, 2001. Disponível em: http://www.scielo. $\mathrm{br} / \mathrm{pdf} / \mathrm{cp} / \mathrm{n} 112 / 16099$ Acesso em: 03 de maio de 2017.

SPOLIN, Viola. Jogos Teatrais: o fichário de Viola Spolin; Tradução de Ingrid Dormien Koudela. 2 ed. São Paulo, São Paulo: Perspectiva, 2012

URIARTE, Urpi Montoya. O que é fazer etnografia para os antropólogos, Ponto Urbe [Online], 11 | 2012, posto online no dia 14 março 2014. Disponível em: <http://pontourbe.revues.org/300>. Acesso em: 03 maios 2017. 